\title{
The suboccipital cavernous sinus
}

\section{Kenan I. Arnautovic, M.D., Ossama Al-Mefty, M.D., T. Glenn Pait, M.D., Ali F. Krisht, M.D., and Muhammad M. Husain, M.D.}

Departments of Neurosurgery and Pathology, University of Arkansas for Medical Sciences, and Laboratory Service, Veterans Administration Medical Center, Little Rock, Arkansas

The authors studied the microsurgical anatomy of the suboccipital region, concentrating on the third segment $\left(\mathrm{V}_{3}\right)$ of the vertebral artery (VA), which extends from the transverse foramen of the axis to the dural penetration of the VA, paying particular attention to its loops, branches, supporting fibrous rings, adjacent nerves, and surrounding venous structures.

Ten cadaver heads ( 20 sides) were fixed in formalin, their blood vessels were perfused with colored silicone rubber, and they were dissected under magnification. The authors subdivided the $\mathrm{V}_{3}$ into two parts, the horizontal $\left(\mathrm{V}_{3} \mathrm{~h}\right)$ and the vertical $\left(\mathrm{V}_{3} \mathrm{v}\right)$, and studied the anatomical structures topographically, from the superficial to the deep tissues. In two additional specimens, serial histological sections were acquired through the $\mathrm{V}_{3}$ and its encircling elements to elucidate their cross-sectional anatomy.

Measurements of surgically and clinically important features were obtained with the aid of an operating microscope.

This study reveals an astonishing anatomical resemblance between the suboccipital complex and the cavernous sinus, as follows: venous cushioning; anatomical properties of the $\mathrm{V}_{3}$ and those of the petrous-cavernous internal carotid artery (ICA), namely their loops, branches, supporting fibrous rings, and periarterial autonomic neural plexus; adjacent nerves; and skull base locations. Likewise, a review of the literature showed a related embryological development and functional and pathological features, as well as similar transitional patterns in the arterial walls of the $\mathrm{V}_{3}$ and the petrous-cavernous ICA. Hence, due to its similarity to the cavernous sinus, this suboccipital complex is here named the "suboccipital cavernous sinus." Its role in physiological and pathological conditions as they pertain to various clinical and surgical implications is also discussed.

Key Words * microsurgical anatomy * function * cavernous sinus * suboccipital cavernous sinus * vertebral artery

The suboccipital region contains the complex of the vertebral artery (VA), its periarterial autonomic neural plexus, its branches, and the adjacent spinal nerves, all of which are cushioned in a venous compartment. This region can be the site of vascular, neoplastic, degenerative, congenital, or traumatological diseases, $[2,8,17,21,22,25]$ the operative management of which demands an in-depth understanding of the complex anatomy. We studied the microsurgical anatomy of this region, 
concentrating on the third segment $\left(\mathrm{V}_{3}\right)$ of the VA, which extends from the transverse foramen of the axis to the dural penetration by the VA. We also studied the loops, branches, supporting fibrous rings, and surrounding venous structures of the $\mathrm{V}_{3}$, as well as the relationships of these anatomical elements to their surrounding structures. Our study revealed an astonishing anatomical resemblance between this complex and the cavernous sinus. A review of the literature showed their related embryological development and functional and pathological features, as well as similar transitional patterns of the structures of the $\mathrm{V}_{3}$ and petrous-cavernous internal carotid artery (ICA) walls. Hence, because of its analogy to the cavernous sinus, we call this suboccipital anatomical complex the "suboccipital cavernous sinus." We also discuss its various functional roles and its relationship to the adjacent structures and the clinical and surgical implications of these factors.

\section{MATERIALS AND METHODS}

The craniocervical regions of ten cadaver heads ( 20 sides) were dissected with the aid of an operating microscope (magnification 4-40). The cadavers previously had been embalmed in a formalin solution. The ICAs, the VAs, and the internal jugular veins (IJVs) were dissected, cannulated, and irrigated with saline to remove any residual blood clots in the lumens. Two colored silicone rubber mixes were prepared by first adding red and blue powder paint (Tempera Powder Paint; Sargen Art, Inc., Hazleton, PA) to the liquid solvent poly-di-methylsiloxane (Dow Corning, Inc., Midland, MI). Silicone rubber was then added immediately before administering the injections. The mixture was prepared so that it was sufficiently fluid to allow perfusion of the smaller blood vessels; it solidified after injection. To further ensure adequate perfusion of the microcirculation, we perfused the arteries individually under pressure (by injecting one ICA while clamping the contralateral ICA and both VAs). Forty hours after the injections were given, the cadavers were ready for dissection. In two additional formalin-fixed specimens, the $\mathrm{V}_{3}$ and its surrounding structures were dissected under the microscope, from the transverse foramen of axis to the dural ring. Serial cross sections were made and embedded in paraffin, and then histological cross sections were cut and stained with hematoxylin and eosin and Masson trichrome. All specimens were examined under the microscope.

The VA is divided into four segments: 1$)$ the pretransverse segment $\left(\mathrm{V}_{1}\right)$, which extends from the origin of the VA to the transverse foramen of the $\mathrm{C}-6$ vertebra; 2$)$ the transverse segment $\left(\mathrm{V}_{2}\right)$, which extends from the transverse foramen of $\mathrm{C}-6$ to the transverse foramen of the axis; 3 ) the suboccipital segment $\left(\mathrm{V}_{3}\right)$, which continues from the transverse foramen of the axis to the dural penetration of the VA; and 4) the intracranial segment $\left(\mathrm{V}_{4}\right)$, which continues intracranially to the junction with the contralateral VA to form the basilar artery.[14,24] We subdivided the $V_{3}$ into two parts: a horizontal segment $\left(V_{3} h\right)$, which is cushioned in a venous compartment, and a vertical segment $\left(\mathrm{V}_{3} \mathrm{v}\right)$, which is surrounded by a venous plexus.

Measurements for the following anatomical structures were obtained with the aid of a microscope: the width of the $\mathrm{V}_{3} \mathrm{~V}$ at the intersection with the anterior ramus of the $\mathrm{C}-2$; the width of the $\mathrm{V}_{3} \mathrm{~h}$ at the origin of the muscular artery; the diameters of the branches of the VA at the sites of origin; the height of the $\mathrm{C}-1$ transverse foramen at the midpoint; and the distances between the midline and the $\mathrm{V}_{3}$ at three levels: 1) the distal (dural) ring; 2) the intersection with the $\mathrm{C}-2$ anterior ramus; and 3) the upper level of the transverse foramen of the atlas. The measurements of the structures were obtained by using calipers and stainless-steel micrometers; the amounts are conservative and can be assumed to be larger in vivo. The 
range and mean statistical values were also obtained.

\section{RESULTS}

We examined the anatomical features of the suboccipital region as they appeared in layers from the superficial to the deep tissues, as follows: 1) the muscular layers; 2) the posterior atlantooccipital membrane; 3) the venous structures; 4) the spinal nerves; and 5) the $V_{3}$ segment of the VA with its loops, branches, and supporting fibrous rings.

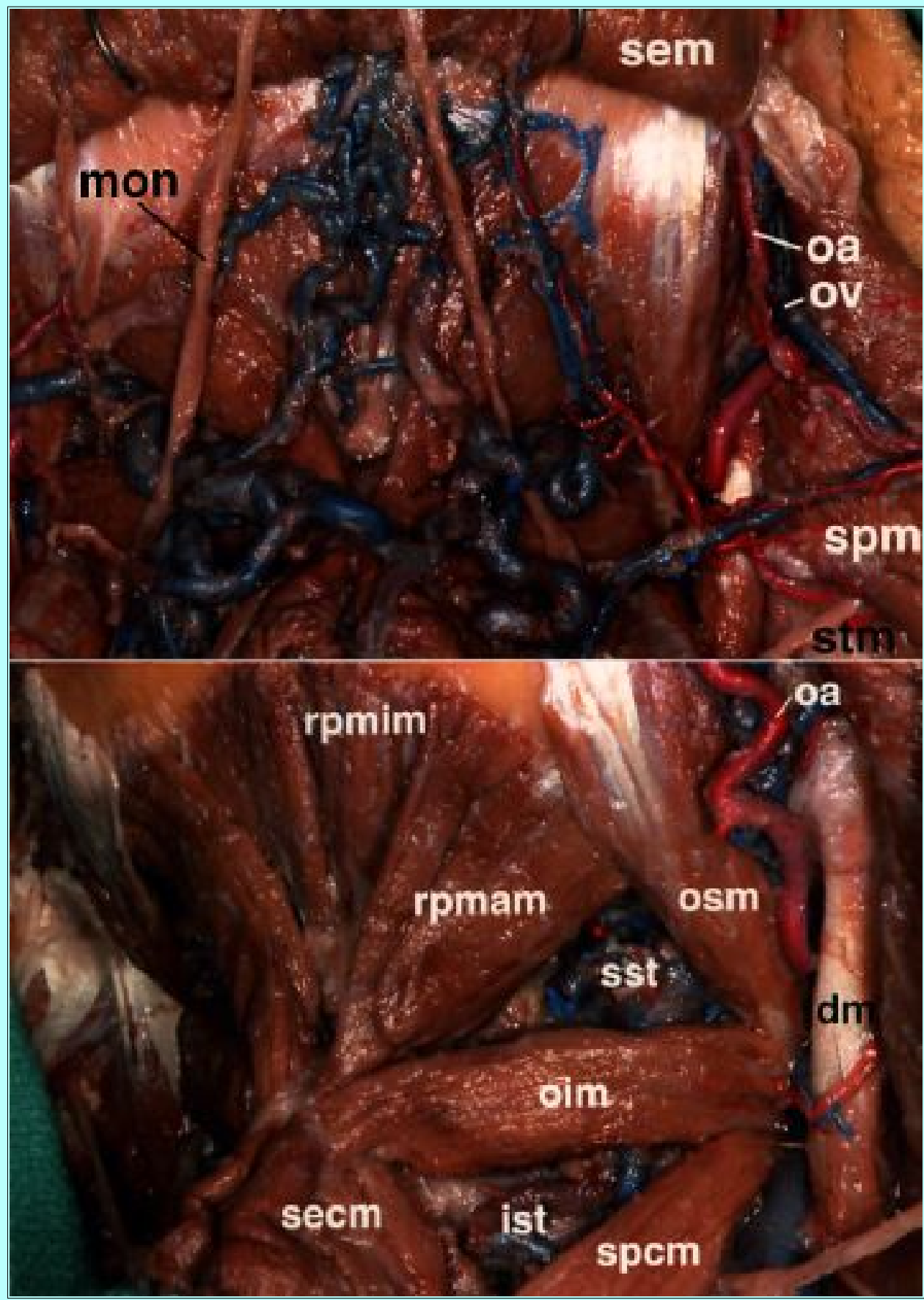

Fig. 1. Photographs of the suboccipital region after reflexion of the superficial and deep muscular layers. Upper: Photograph showing the suboccipital venous plexus located on the deep muscular layer. The muscles of the first and second layers are reflected: semispinalis capitis muscle (sem) superiorly and sternocleidomastoid (stm) and splenius capitis (spm) muscles laterally. The major occipital nerve (mon) arises here from the posterior ramus of 
C-2 nerve and ascends to pierce the semispinalis muscle. Note also the OA (oa) and the occipital vein (ov), the latter of which connects the mastoid emissary vein and the suboccipital venous plexus. Lower: Photograph showing the deep muscular layer (right side). The obliquus capitis superior (osm), obliquus capitis inferior (oim), and rectus capitis posterior major (rpmam) muscles create the superior suboccipital triangle (sst). The oim, splenius cervicis (spcm), and semispinalis cervicis ( $\mathrm{secm}$ ) muscles create the inferior suboccipital triangle (ist). Note also the OA, the rectus capitis posterior minor muscle (rpmim), and the digastric muscle (dm). Click here to view abbreviation list.

\section{Muscular Layers}

The $\mathrm{V}_{3}$ is covered by three layers of muscles: superficial, intermediate, and deep, as noted in previous anatomical descriptions.[14,35,37] A rich suboccipital venous plexus is located between the intermediate and deep muscular layers (Fig. 1 upper). At the occipitoatlantal interspace, the muscles of the deep layer, namely the obliquus capitis superior and inferior muscles and the rectus capitis posterior major muscle, create the superior suboccipital triangle. The floor of this triangle consists of the posterior arch of the atlas and the posterior atlantooccipital membrane. Located ventrally to the latter is the venous compartment that contains the $\mathrm{V}_{3} \mathrm{~h}$, the muscular artery of the $\mathrm{V}_{3} \mathrm{~h}$, the posterior meningeal artery of the $\mathrm{V}_{3} \mathrm{~h}$, the periarterial autonomic neural plexus, and the $\mathrm{C}-1$ nerve branching into anterior and posterior rami. In the atlantoaxial region, the obliquus capitis inferior and the semispinalis and splenius cervicis muscles delineate the inferior suboccipital triangle. This triangle contains the $\mathrm{V}_{3} \mathrm{v}$, the periarterial autonomic neural plexus, the muscular and radiculomuscular arteries of the $\mathrm{V}_{3} \mathrm{v}$, the $\mathrm{VA}$ venous plexus (VAVP) around the $\mathrm{V}_{3} \mathrm{v}$, and the $\mathrm{C}-2$ nerve branching into anterior and posterior rami (Fig. 1 lower).

\section{Posterior Atlantooccipital Membrane}

The posterior atlantooccipital membrane, located ventral to the deep muscular layer covering the $V_{3} h$, is stretched at the foramen magnum between the inferior border and the posterior surface of the occipital bone and the posterior arch of the atlas. Close to its lateral border is an opening, which we delineate as the foramen of the posterior atlantooccipital membrane (Fig. 2). The anatomical elements coursing through this foramen are: 1) the communicating vein between the suboccipital venous plexus and the venous compartment that cushions the $\mathrm{V}_{3} \mathrm{~h}$; 2) the branches of the posterior ramus of the $\mathrm{C}-1$ nerve (the suboccipital nerve) that innervate the suboccipital muscles; and 3) the muscular artery of the $V_{3} h$, which communicates with the branches of the occipital artery (OA). 


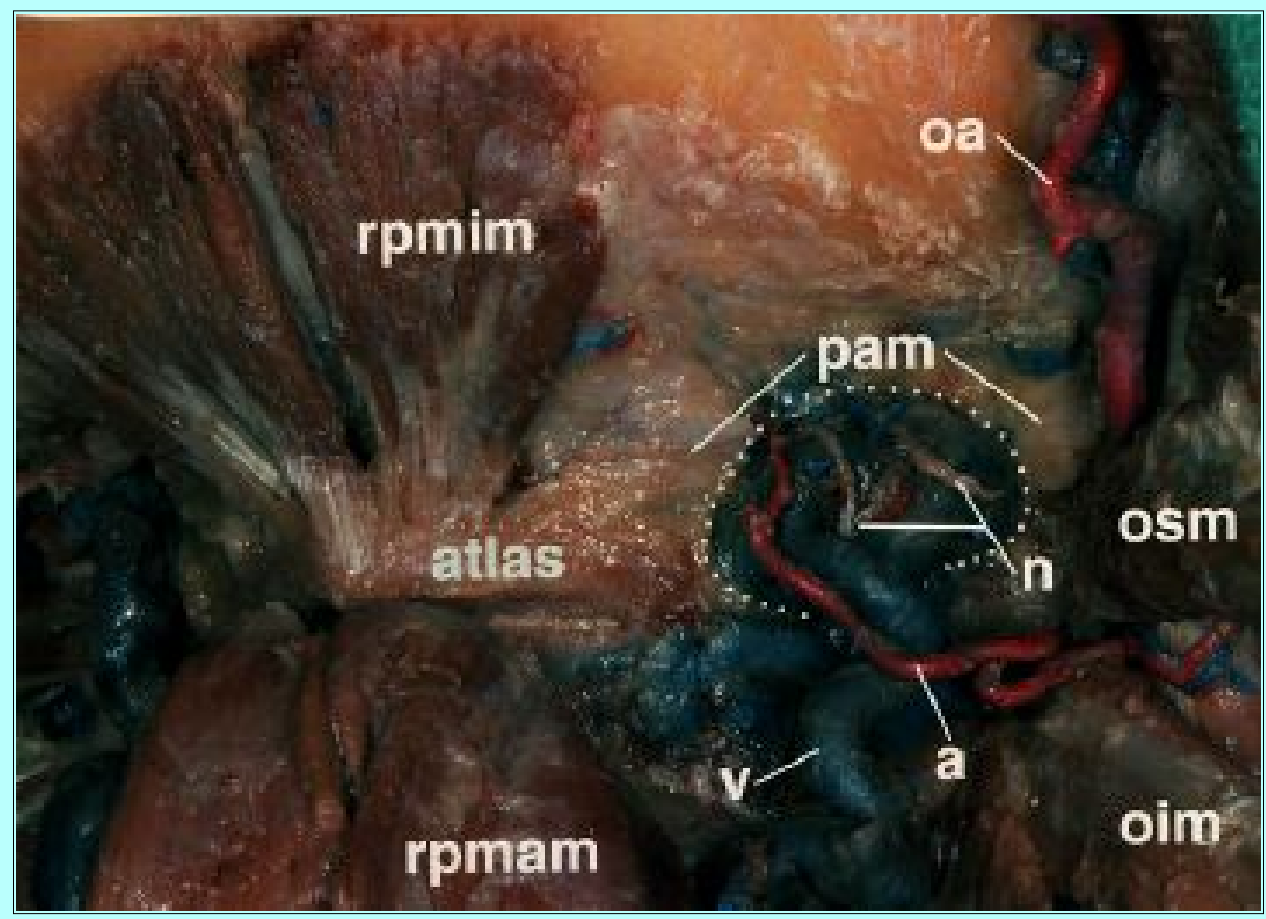

Fig. 2. Photograph of cadaveric head (right side) revealing the posterior atlantooccipital membrane (pam). The pam is stretched between the occipital bone and the atlas. Close to its lateral border it displays a foramen of the posterior atlantooccipital membrane (dots). Coursing throughout this foramen are the muscular artery of $\mathrm{V}_{3} \mathrm{~h}(\mathrm{a})$, the anastomotic vein (v), and the branches of the posterior ramus of C-1 nerve (n). The rpmim is in position, whereas the osm is reflected laterally, and the oim and rpmam muscles are reflected inferiorly. The OA (oa) is more lateral. Click here to view abbreviation list.

\section{Suboccipital Venous Structures}

The venous structures in the suboccipital region are: (1) the suboccipital venous plexus; (2) the venous compartment cushioning the $\mathrm{V}_{3} \mathrm{~h}$; (3) the VAVP around the $\mathrm{V}_{3} \mathrm{v}$; and (4) the vertebral venous plexus (VVP) related to the spine.

The suboccipital venous plexus is located between the intermediate and deep muscular layers (Fig. 1) and continues inferiorly into the deep cervical vein. The suboccipital venous plexus communicates with the following structures: 1 ) the venous compartment cushioning the $\mathrm{V}_{3} \mathrm{~h}$ via the anastomotic vein that passes through the foramen of the posterior atlantooccipital membrane (Fig. 2); 2) the VAVP around the $\mathrm{V}_{3} \mathrm{v}$; and 3) the VVP (the suboccipital venous plexus), which communicates with both the anastomotic vein at the atlantooccipital interspace (Fig. 3 A, B, and C); and (4) the transverse sigmoid sinus via the mastoid emissary and occipital veins (Fig. 1). 


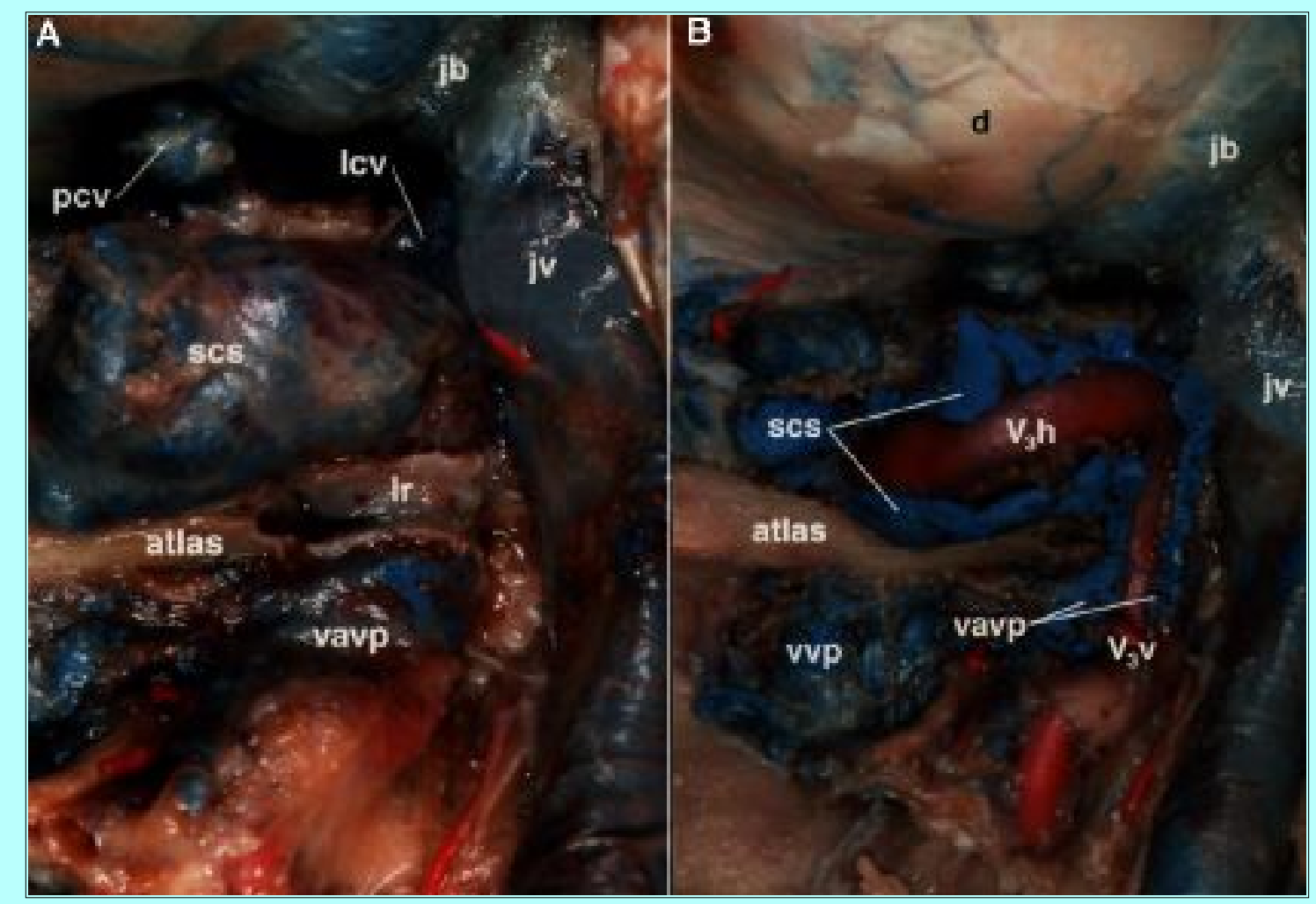

Fig. 3. Depictions of anatomy of the suboccipital region. A: Photograph showing the right suboccipital cavernous sinus (scs) receiving the posterior condylar (pcv) and the lateral condylar veins (lcv) from the jugular bulb (jb) and the IJV (jv). The anterior condylar vein is hidden anteroinferiorly. The lateral ring (lr) encases the scs, the $\mathrm{V}_{3}$, and the periarterial autonomic neural plexus in the revealed transverse foramen of the atlas. The VAVP (vavp) around the $\mathrm{V}_{3} \mathrm{~V}$ is an inferior continuation of the scs. B: Photograph showing partial removal of SCS (right side), revealing the $\mathrm{V}_{3} \mathrm{~h}$. This segment continues inferior to the revealed transverse foramen of the atlas by the VAVP (vavp), which is also partially removed, revealing the $\mathrm{V}_{3} \mathrm{v}$. The VAVP communicates with the VVP and with the suboccipital venous plexus. Note also the posterior fossa dura (d), jb, and the IJV (jv). Click here to view abbreviation list.

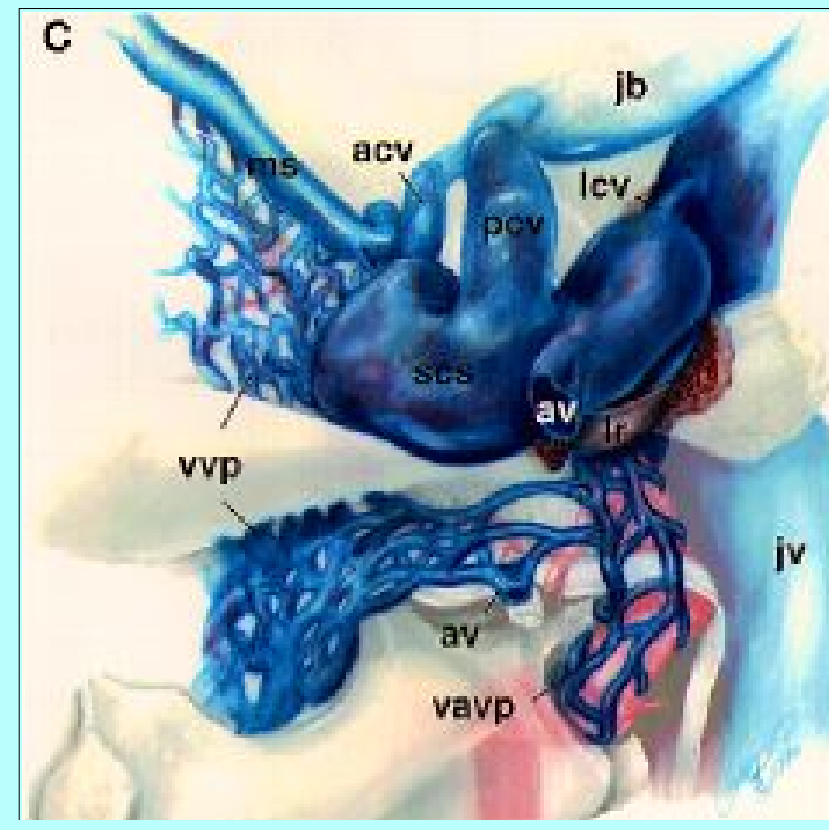

Fig. 3. C: Illustration depicting the right scs with its connections with the jb and IJV (jv): anterior condylar vein (acv); pcv; and lcv. It is also communicating with the marginal sinus (ms); the VVP (vvp); and the suboccipital venous plexus (via the anastomotic vein [av]). Below the lr the scs is continued by the VAVP (vavp). This plexus is also communicating with the VVP (vvp) and with the suboccipital venous plexus (via the av).

Fig. 3. D: Photomicrograph showing a histological cross-section of the right scs (midportion). Note the pam, the membrane of the suboccipital cavernous sinus $(\mathrm{m})$, and its venous spaces (stars) cushioning the $\mathrm{V}_{3} \mathrm{~h}$ 


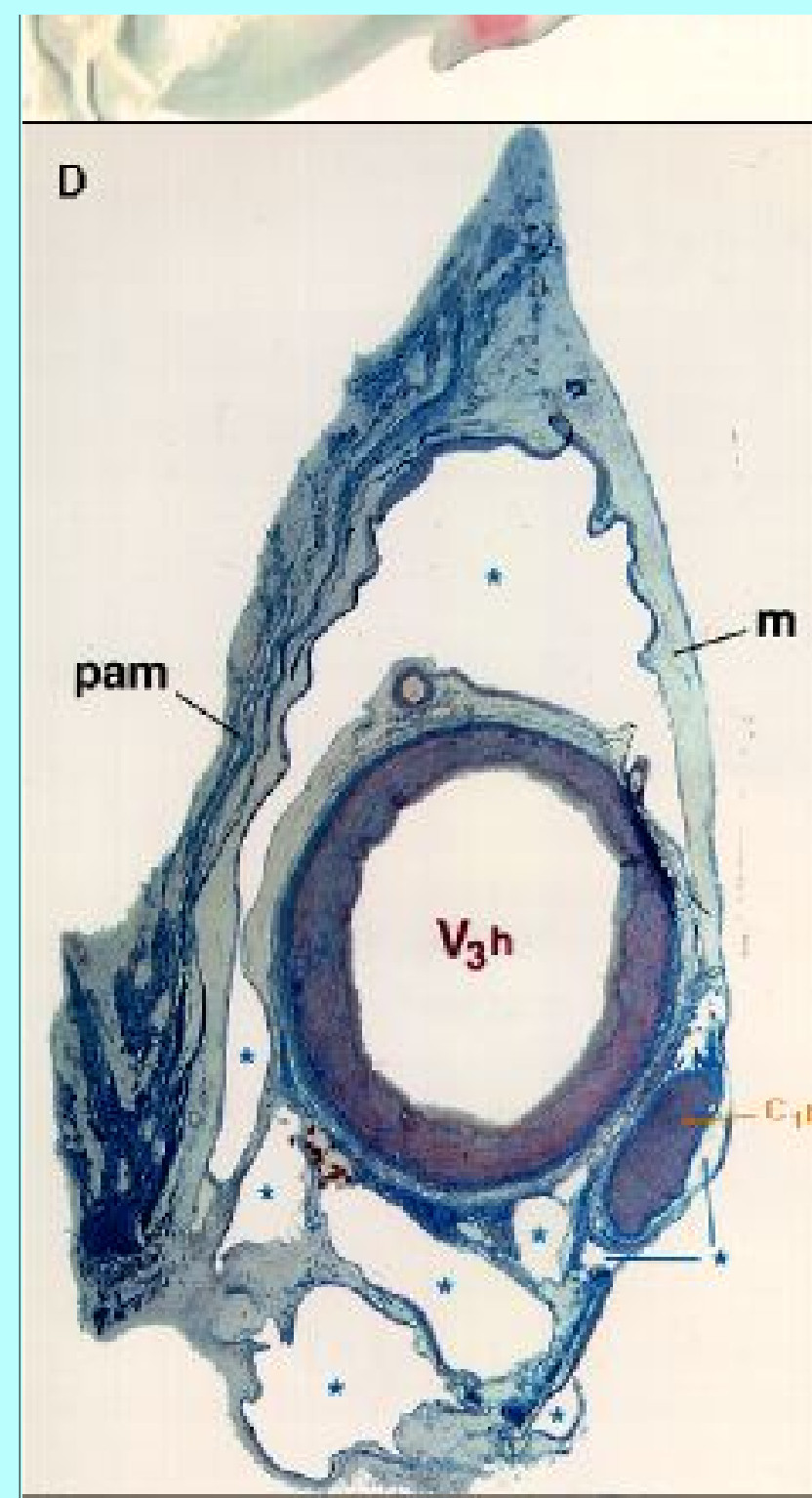

and the $\mathrm{C}-1$ nerve $\left(\mathrm{C}_{1} \mathrm{n}\right)$. Masson's trichrome, original magnification $\mathrm{X} 13$.

Fig. 3. E: Photomicrographs showing a histological cross-section of the right $\mathrm{V}_{3} \mathrm{~V}$ complex at its

intersection by the anterior ramus of the $\mathrm{C}-2$ nerve $\left(\mathrm{C}_{2}\right.$ ar). Note the $\mathrm{V}_{3} \mathrm{v}$, the VAVP (vavp) at the posteromedial aspect of the artery (consisting of several venous trunks), and the fibrous adhesion between the $\mathrm{V}_{3} \mathrm{~V}$ and the $\mathrm{C}_{2}$ ar (arrow). $\mathrm{H} \& \mathrm{E}$, original magnification $\mathrm{X} 13$. Click here to view abbreviation list.

We found that the venous compartment in the suboccipital region, bordered proximally by the lateral (periosteal) ring, distally by the distal (dural) ring, inferiorly by the posterior arch of the atlas, ventrally by the dura and the capsule of the atlantooccipital condylar joint, and dorsally by the posterior atlantooccipital membrane, is a structure strikingly similar to the cavernous sinus. It is surrounded by a fibrous membrane and contains and cushions the $\mathrm{V}_{3} \mathrm{~h}$, the muscular artery of the $\mathrm{V}_{3} \mathrm{~h}$, the posterior meningeal artery, the periarterial autonomic neural plexus, and the $\mathrm{C}-1$ nerve branching into anterior and posterior rami (Fig. $3 \mathrm{D}$ ). It communicates with 1) the contralateral sinus via the internal VVP; 2) the occipital sinus via the marginal sinus; and 3) the jugular bulb and vein via, first, the anterior condylar vein, which

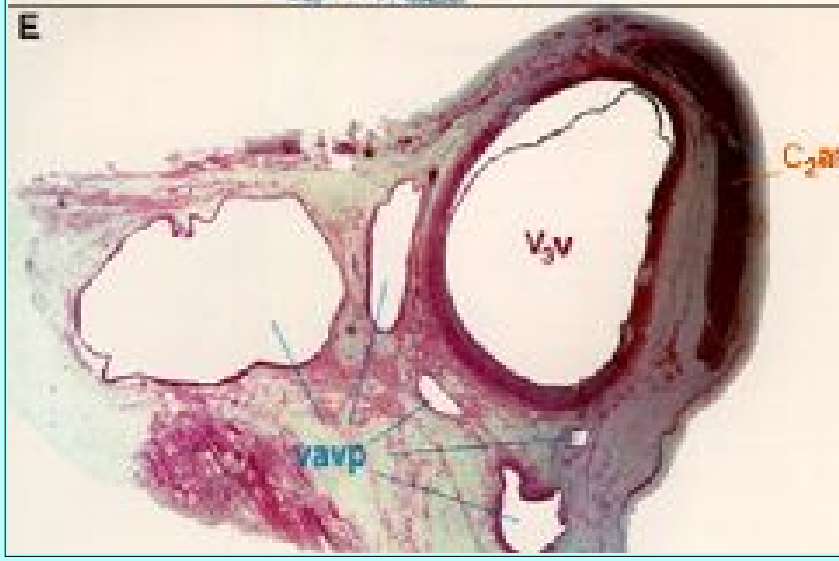
accompanies the hypoglossal nerve and meningeal branch of the ascending pharyngeal artery along the hypoglossal canal (anterior condylar canal); second, the posterior condylar vein, which exits from the posterior condylar canal at the condylar fossa located posterior to and above the occipital condyle; and third, the lateral condylar vein, which connects the jugular vein and the venous compartment cushioning the $\mathrm{V}_{3} \mathrm{~h}$ and is lateral to the occipital condyle (Fig. 3 A, B, and C); and 4) the suboccipital venous plexus via the anastomotic vein coursing through the foramen of the atlantooccipital

membrane.

The suboccipital venous compartment cushioning the $\mathrm{V}_{3}$ h continues below the transverse foramen of the atlas, gradually becoming the VAVP (the venous plexus around the $\mathrm{V}_{3} \mathrm{v}$ ). This plexus has a number of venous trunks (average four, range three-six) mutually interconnected by venules and located predominantly at the medioposterior aspect of the $\mathrm{V}_{3} \mathrm{~V}$ (Fig. $3 \mathrm{E}$ ). It communicates with the $\mathrm{VVP}$ and the suboccipital venous plexus (Fig. 3 A, B, and C). More distally, the VAVP continues below the axis as two or three vertebral veins that merge into one trunk that enters the brachiocephalic vein. 
The internal VVP, a rich venous network, is contained within the dural leaflets at the occipitoatlantal interspace. It is an inferior continuation of the occipital and marginal dural sinuses, as well as of the basilar venous plexus. At the atlantoaxial interspace, this plexus has an external component (external VVP) located predominantly around the axis and continuing farther below it. It connects the two contralateral venous compartments around the $\mathrm{V}_{3} \mathrm{~h}$ at the occipitoatlantal interspace and the two contralateral VAVPs at the atlantoaxial interspace (Figs. 3 A, B, C and 4).

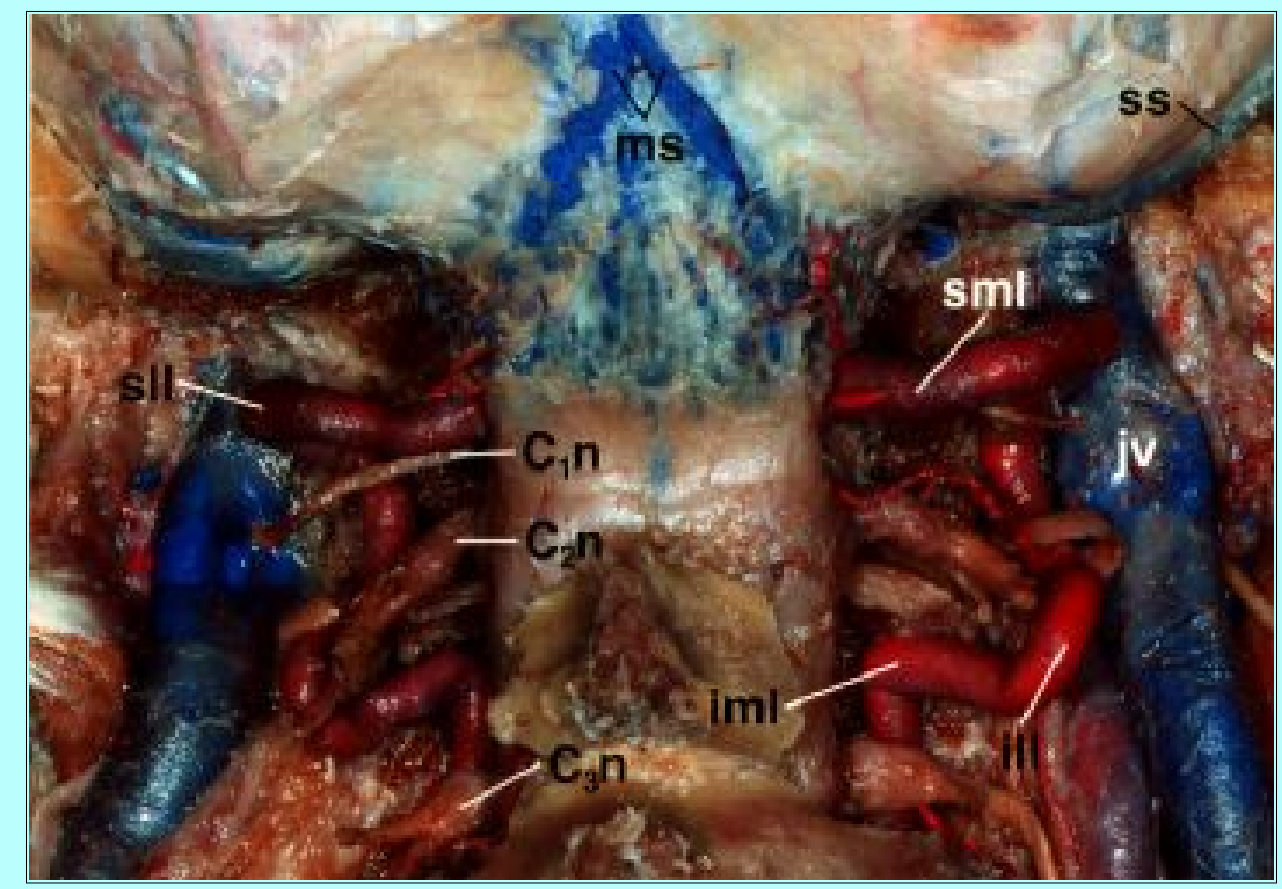

Fig. 4. Photograph completely revealing the $\mathrm{V}_{3}$ after the removal of the atlas and axis (except the spinous process). The $\mathrm{V}_{3}$ has four vascular loops: inferior medial loop (iml); inferior lateral loop (ill); superior lateral loop (sll); and superior medial loop ( $\mathrm{sml}$ ). Note also the marginal dural venous sinus (ms), the sigmoid sinus (ss), the jv, and the $\mathrm{C}-1\left(\mathrm{C}_{1} \mathrm{n}\right), \mathrm{C}-2$ $\left(\mathrm{C}_{2} \mathrm{n}\right)$, and $\mathrm{C}-3\left(\mathrm{C}_{3} \mathrm{n}\right)$ nerves. Click here to view abbreviation list.

\section{Spinal Nerves}

Two spinal nerves, the $\mathrm{C}-1$ and the $\mathrm{C}-2$, are adjacent to the $\mathrm{V}_{3}$.

The C-1 Nerve. Exiting extradurally at the inferior aspect of the $\mathrm{V}_{3} \mathrm{~h}$ is the $\mathrm{C}-1$ nerve (Fig. 4); both the artery and the exiting nerve are encircled by the distal ring. The $\mathrm{C}-1$ nerve is located in the depth of the superior suboccipital triangle and within the sulcus of the VA of the posterior arch of the atlas, where it divides into anterior and posterior rami. The anterior ramus continues below the $V_{3} h$, passes between the obliquus capitis superior and rectus capitis anterior muscles, and contributes to the cervical plexus. The posterior ramus exits through the foramen of the posterior atlantooccipital membrane, branching out and innervating the suboccipital muscles (Fig. 2).

The C-2 Nerve. At the occipitoatlantal interspace, in the depth of the inferior suboccipital triangle, the C-2 nerve (Fig. 4) exits extradurally and divides into anterior and posterior rami. The anterior ramus is attached to the $\mathrm{V}_{3} \mathrm{~V}$ with a fibrous adhesion (Fig. $3 \mathrm{E}$ ); it curves around the artery ventral to the posterior intertransverse muscle and contributes to the cervical plexus. The posterior ramus courses posteriorly 
below the inferior obliquus muscle and divides into a medial branch (the major occipital nerve) and a lateral branch, the latter of which innervates the suboccipital intermediate muscular layer.

\section{Vascular Loops of the $V_{3}$ Segment}

The $V_{3}$ possesses four vascular loops (Fig. 4). The first, the inferior medial loop, which directs the artery laterally and slightly posteriorly, appears at the transverse foramen of the axis. The next loop, the inferior lateral loop, continues immediately, directing the artery upward and slightly anterior toward the transverse foramen of the atlas. The third, the superior lateral loop, is located at the point where the $\mathrm{V}_{3} \mathrm{~V}$ turns into a horizontal position $\left(\mathrm{V}_{3} \mathrm{~h}\right)$ in the sulcus of the posterior arch of the atlas. In two arteries (20\%), this bone groove was transformed into the canal by the bone ring. The fourth loop, the superior medial loop, surrounds the condyle of the atlas and brings the $V_{3}$ to its dural foramen. This part of the $V_{3}$ is connected to the capsule of the atlantooccipital articulation by the retroglenoid ligament, a strong and wide fibrous adhesion.

At the atlantoaxial interspace, the $\mathrm{V}_{3} \mathrm{~V}$ is intersected dorsally by the anterior ramus of the $\mathrm{C}-2$ nerve, which is attached to the artery by fibrous adhesion (Fig. 3 E). A fine periarterial autonomic neural plexus encircles the $\mathrm{V}_{3}$ in its entire length (Fig. 5).

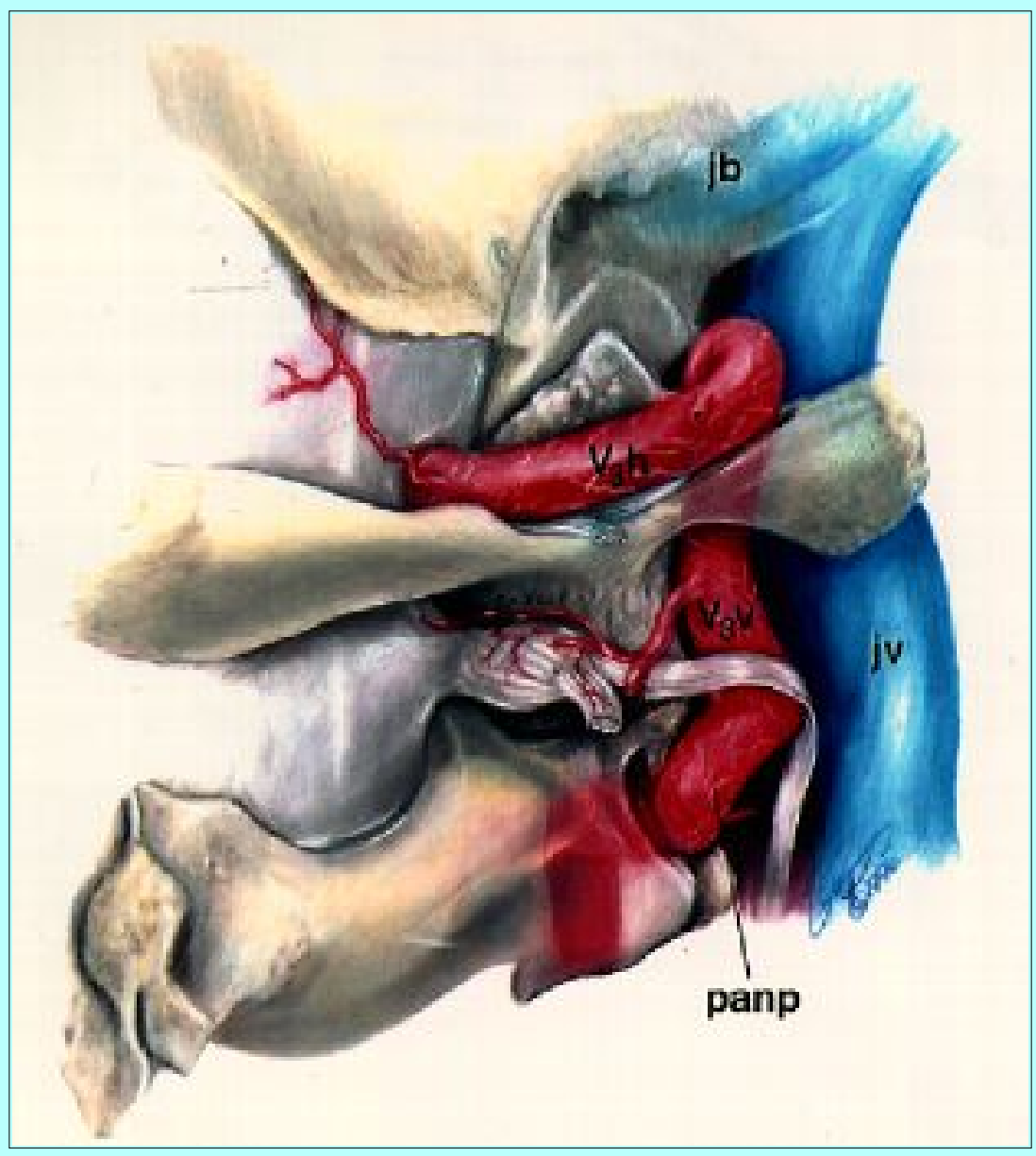

Fig. 5. Illustration depicting the $\mathrm{V}_{3}$ segment of the VA (right side), including the vertical $\left(\mathrm{V}_{3} \mathrm{v}\right)$ and the horizontal $\left(\mathrm{V}_{3} \mathrm{~h}\right)$ parts. Note also the $\mathrm{jb}$ and IJV (jv), and the periarterial autonomic neural plexus (panp). Click here to view abbreviation list. 
Tables 1, 2, and 3 provide the measurements obtained.

\begin{tabular}{|c|c|c|c|c|}
\hline \multicolumn{5}{|c|}{$\begin{array}{c}\text { TABLE } 1 \\
\text { COMPARISON OF VA, WIDTHS (IN MLLIMETERS) IN } 10 \text { CADAVERIC HEADS* }\end{array}$} \\
\hline \multirow[b]{2}{*}{ V3 Subdivisi on } & \multicolumn{2}{|c|}{ Left } & \multicolumn{2}{|c|}{ Right } \\
\hline & Range & Mean & Range & Mean \\
\hline $\begin{array}{l}V_{3} v \text { (intersection w/anterior ramus } \\
\text { of the } c-2 \text { nerve) }\end{array}$ & $4.0-6.1$ & 4.8 & $3.5-5.9$ & 4.6 \\
\hline$V_{3} h$ (origin of the muscular artery) & $3.2-5.2$ & 4.2 & $3.0-5.1$ & 4.0 \\
\hline
\end{tabular}

\begin{tabular}{|cc|}
\hline & TABLE 2 \\
\multirow{2}{*}{ COMPARISON OF THE HE GHT OF THE TRANSVERSE FORAMEN OF THE ATLAS AT } \\
THE MIDPORTION IN 10 CADAVER K HEADS*
\end{tabular}

\begin{tabular}{|c|c|c|c|c|}
\hline \multicolumn{5}{|c|}{$\begin{array}{c}\text { TABLE } 3 \\
\text { DISTANCES (IN MILLIMETERS) BETWEEN THE MIDLINE AND THE V/Y AND V/3H } \\
\left.\text { PARTS OF THE THRD SEGMENT ( } V_{3}\right) \text { OF THE VA AT DIFFERENT LEVELS }\end{array}$} \\
\hline \multirow[b]{2}{*}{ Level } & \multicolumn{2}{|c|}{ Distance: Lt } & \multicolumn{2}{|c|}{ Distance: $\mathrm{Rt}$} \\
\hline & Range & Mean & Range & Mean \\
\hline $\begin{array}{l}V_{3} \text { v (intersection w/anterior ramus } \\
\text { of } O 2 \text { ner we) }\end{array}$ & $27.4-36.1$ & 30.8 & $26.6-37.3$ & 30.8 \\
\hline $\begin{array}{l}W_{3} \text { h (distal ring) } \\
V_{3} \text { h (upper border of the transwerse } \\
\text { foramen of the attas) }\end{array}$ & $\begin{array}{l}11.2-19.2 \\
24.0-36.6\end{array}$ & $\begin{array}{l}14.7 \\
31.4\end{array}$ & $\begin{array}{l}12.4-19.2 \\
23.5-35.1\end{array}$ & $\begin{array}{l}14.6 \\
30.8\end{array}$ \\
\hline
\end{tabular}

\section{Fibrous Rings}

In the transverse foramen of the atlas, a fibrous periosteal ring, herein described as the lateral ring, surrounds the venous compartment that cushions the $\mathrm{V}_{3} \mathrm{~h}$, the periarterial autonomic neural plexus, and the $\mathrm{V}_{3}$ (Fig. $3 \mathrm{~A}$ ).

At the point where the VA penetrates the dura is a dural ring, herein described as the distal ring; it encircles (1) the VA; (2) the periarterial autonomic neural plexus; (3) the C-1 nerve (located below the artery); and (4) the extradural origin (present in $10 \%$ of specimens) of the posterior spinal artery at the posteromedial aspect of the ring (Fig. 6). 


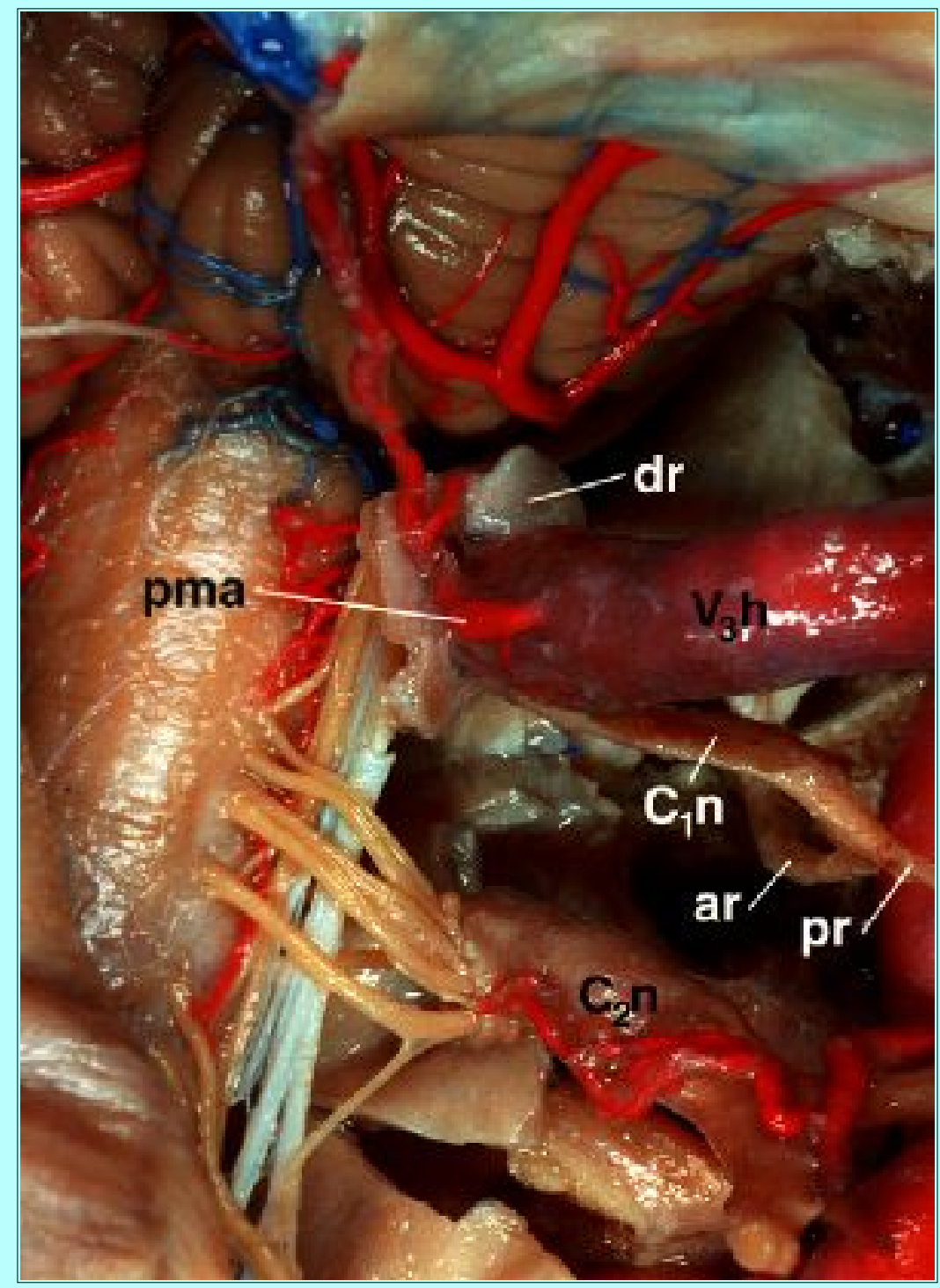

Fig. 6. Photograph showing opened right distal ring $(\mathrm{dr})$ around the right $\mathrm{V}_{3} \mathrm{~h}\left(\mathrm{~V}_{3} \mathrm{~h}\right)$. Note the $\mathrm{C}-1$ nerve $\left(\mathrm{C}_{1} \mathrm{n}\right)$ below the artery with the anterior (ar) and posterior (pr) rami, the $\mathrm{C}-2$ nerve $\left(\mathrm{C}_{2} \mathrm{n}\right)$, and the posterior meningeal artery (pma) arising from the dorsomedial part of the $\mathrm{V}_{3} \mathrm{~h}$. Click here to view abbreviation list.

\section{Arterial Branches of the $V_{3}$ Segment}

The $V_{3} \mathrm{v}$ and the $\mathrm{V}_{3} \mathrm{~h}$ each have two constant branches. These branches are described below.

Muscular Artery of $V_{3} v$. This artery arises ventral to the anterior ramus of the C-2 nerve and communicates further ventrally with the branches of the ascending pharyngeal artery (Fig. 7 left). In 90\% of the samples it was the same size on both sides; in $10 \%$ it was larger on the left side (mean diameter 0.4 $\mathrm{mm})$. 


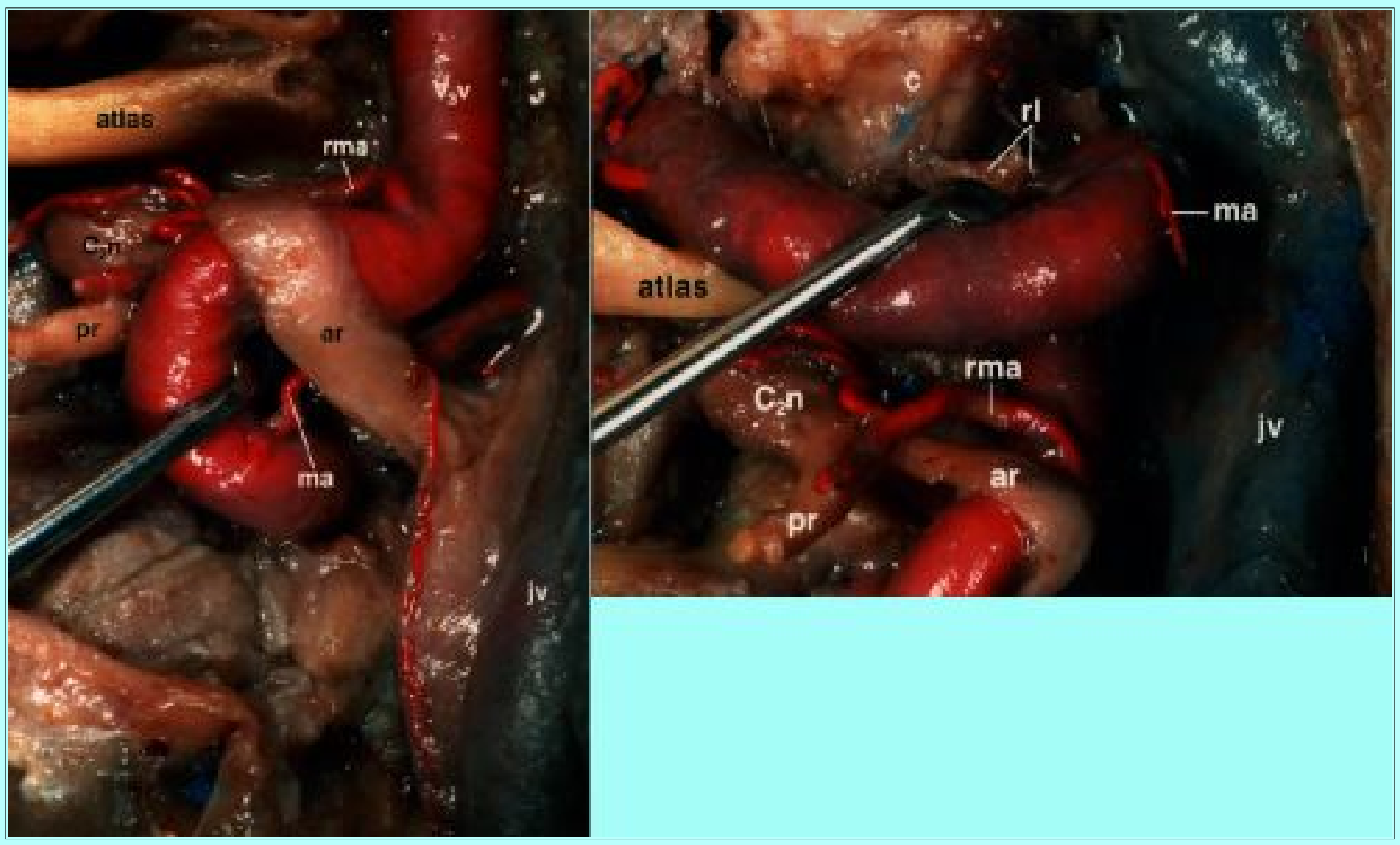

Fig. 7. Photographs showing segments of the right $\mathrm{V}_{3} \mathrm{v}$ and $\mathrm{V}_{3} \mathrm{~h}$. Left: The $\mathrm{V}_{3} \mathrm{v}$ has two arterial branches: the muscular artery (ma), arising ventral to the ar of $\mathrm{C}_{2} \mathrm{n}$, and the radiculomuscular artery (rma). Note $\mathrm{C}_{2} \mathrm{n}$ with its ar and pr. Right: Photograph showing the ma of the $\mathrm{V}_{3} \mathrm{~h}$. Note also the condyle (c), the rma of $\mathrm{V}_{3} \mathrm{v}$ dividing into two branches, the $\mathrm{j} v$, the retroglenoid ligament $(\mathrm{rl})$, and the $\mathrm{C}_{2} \mathrm{n}$ with its ar and pr. $\underline{\text { Click here to view abbreviation }}$ list.

Radiculomuscular Artery of $V_{3} v$. This artery arises below the transverse foramen of the atlas and gives rise to the radiculomedullary branch, which accompanies the C-2 nerve laterally, vascularizing the C-2 ganglion, the C-2 nerve, and the spinal cord; and the muscular branch, which accompanies the posterior ramus of the $\mathrm{C}-2$ nerve (Fig. 7). This artery was found to be the largest branch of the $\mathrm{V}_{3}$. It was the same width on both sides in all the specimens (mean diameter $1 \mathrm{~mm}$ ).

Muscular Artery of $V_{3} h$. This artery courses posteriorly through the foramen of the posterior atlantooccipital membrane, vascularizes the muscles of the deep muscular layer and surrounding tissue, and communicates with the branches of the OA (Fig. 7 right). In $70 \%$ of the samples it was the same size on both sides; in $30 \%$ it was larger on the right side (mean diameter $0.5 \mathrm{~mm}$ ).

Posterior Meningeal Artery of $V_{3} h$. This artery arises at the superior surface of the $\mathrm{V}_{3} \mathrm{~h}$ (at the superior medial loop) and vascularizes the neighboring portion of the posterior fossa dura, the falx cerebelli, the posterior portion of the tentorium, and the adjacent squama of the temporal bone (Fig. 6). The diameters on the two sides were the same in $70 \%$ of the samples, larger on the right side in $20 \%$, and larger on the left side in $10 \%$ (mean diameter $0.8 \mathrm{~mm}$ ).

In addition to these consistent branches, we found an arterial branch entering the posterior condylar canal (average diameter $0.4 \mathrm{~mm}$ ) in two $\mathrm{V}_{3} \mathrm{~h}$ segments $(10 \%)$, and an extradural origin of the posterior spinal 
artery (average diameter $1 \mathrm{~mm}$ ) in two other $\mathrm{V}_{3} \mathrm{~h}$ segments $(10 \%)$.

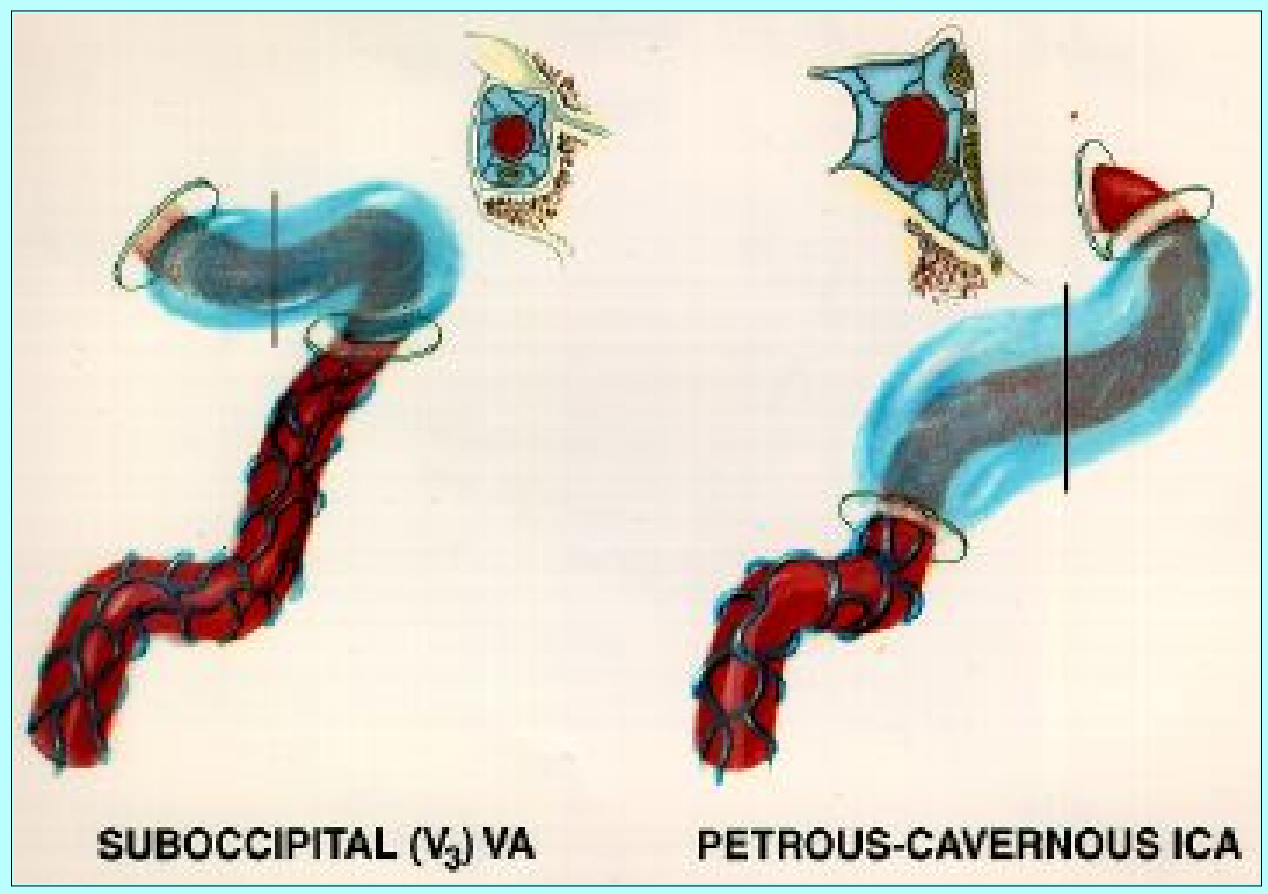

Fig. 8. Illustration depicting the suboccipital $\left(\mathrm{V}_{3}\right)$ segment of the VA and the petrous-cavernous ICA[1,14,52,68] depicting the similarity of the two arterial segments (right sides). Note also the similarity between the cross-sections of the suboccipital cavernous sinus cushioning the $\mathrm{V}_{3} \mathrm{~h}$ (left inset)[72] and the cavernous sinus cushioning the ICA (right inset).[52,67]

\section{DISCUSSION}

The $\mathrm{V}_{3}$ segment of the VA and its relation to the surrounding venous structures showed striking similarities to the petrous-cavernous ICA and its surrounding venous structures (Fig. 8). The cavernous sinus in the lateral sellar compartment was named by Winslow, who in 1732 compared it to the corpus cavernosum of the penis. This misnomer has been widely accepted, despite controversy concerning the term.[3,50,51,62] Parkinson[50] in particular has been a strong advocate for the term "lateral sellar compartment." Parkinson[50,51] and Dolenc[15] are credited with providing detailed microsurgical anatomical studies of the cavernous sinus space and with pioneering surgery in this region. Because of the similarities between it and the suboccipital venous compartment that cushions the $V_{3}$ at the occipitoatlantal interspace, we posit that the most appropriate term for the latter is the suboccipital cavernous sinus.

Our review of the literature reveals that these similarities were also noticed in 1964 by Zolnai,[72] who stated that "between the atlas and the foramen magnum exists the venous atlantooccipital sinus, which encircles the VA, and is similar to the cavernous sinus by its structure" and that because the sinus completely encircles the VA, it may be mistaken for the artery itself. In 1969, Yasargil[69] noted that the ICA enters the bony petrous carotid canal accompanied by two veins (one each on the convex and concave sides) and continues into the cavernous sinus, in which the veins communicate with the surrounding venous structures. Similarly, he stated, the VA is enveloped within its canal by the venous plexus, which communicates with the VVP. The arterial walls in both ICA and VA at these segments gradually transform from extracranial to intracranial patterns, losing their elastic, collagenous, and 
muscular elements, thus becoming thinner. Both arterial segments are encircled by periarterial autonomic neural plexuses. Other authors have outlined the similar embryological development of the ICAs and VAs,[41,54] as well as the uniform development of the cranial venous system and its drainage pathways.[26,27,48]

The similarities between the anatomical complexes of the petrous-cavernous ICA and the suboccipital $\left(\mathrm{V}_{3}\right)$ segment of the VA far exceed the traits noted above. For one, both are exclusive brain blood suppliers, entering intracranial compartments after significant portions of their lengths have been cushioned in venous compartments (Fig. 8). Also, both arteries have four arterial loops, are encased by arterial fibrous rings (which delineate the venous compartments), and are accompanied by nerves (cranial and spinal nerves, respectively). Both arteries give forth branches within the venous compartments that communicate with surrounding branches, vascularizing the surrounding structures and playing an important role in obstructive cerebrovascular conditions. Furthermore, the venous compartments surrounding the petrous-cavernous ICA and the $\mathrm{V}_{3}$ play quite similar (if not the same) roles in physiological conditions (for example, accessory venous drainage from the intracranium and regulation of intracranial pressure) and pathological conditions (for example, metastatic spread of tumors or infections from neighboring or remote extracranial regions; spontaneous or traumatic arteriovenous fistulas). Both structures are often affected by the same (or similar) pathological conditions and are encountered during certain skull base approaches. Finally, under certain circumstances, these anatomical complexes probably become a single functional unit (for example, providing simultaneous accessory venous drainage from the intracranium).

We hypothesize that the loopings of the $\mathrm{V}_{3}$ and the petrous-cavernous ICA (which also increase the contact surface of arteries cushioned by veins), their intraluminal pressures, and their pulsations are interrelated with the pressures of their venous compartments. In turn, all apparently affect intracranial pressure in some manner. Further studies concerning these phenomena are needed.

\section{Anatomical Considerations}

The four loops of the $\mathrm{V}_{3}$ have been described as first-through-fourth contours[19] or curves.[24] In neurosurgical communications, "loop" is the preferred term. They can be divided into four types according to their shapes.[38] The degrees of curvature of the inferior medial and the inferior lateral loops (first and second contours) appear to be related to aging.[19] The retroglenoid ligament, which connects the superior medial loop (fourth contour) to the atlantooccipital articulation (Fig. 7 right), may be ossified, making surgical dissection of the artery more difficult. At the interval between $0.5 \mathrm{~cm}$ before and $0.5 \mathrm{~cm}$ after the piercing of the dura, the thicknesses of the adventitial and medial arterial coats are drastically diminished, and the elastic fibers in the media and external elastic lamina of the VA are grossly reduced.[19,24,37,66,69] The dura at the occipitoatlantal interspace is thicker[55] and contains the internal VVP within its leaflets (Figs. 3C and 4).

The $V_{3}$ is surrounded by the periarterial autonomic neural plexus (Fig. 6). It is formed by the unmyelinated nerve fibers arising from cervical ganglions (predominantly inferior) and upper cervical nerves and consists of fine branching and communicating nerves that are directed lengthwise and diagonally in the adventitia, continuing around the $\mathrm{V}_{3}$ into the cranial cavity and supplying the endocranial blood vessels distally. This plexus also supplies the lower cranial nerves by the neural rami. We confirmed that the vertebral nerve is not located above the level of the C-3 vertebra.[24,32-38] 
Of interest is the discovery by Parke and Valsamis[49] of an "ampulloglomerular organ" at the atlantooccipital interspace and within the suboccipital cavernous sinus, adjacent to the dural penetration of the VA. This formation was described as a group of venous sacculations connected to a dural sinus, associated with a system of glomerular arteriovenous formations and numerous nerves, and capable of responding to changes in venous pressures. Structurally it resembled the carotid and aortic bodies. This finding, revealing yet another similarity between the petrous-cavernous ICA and the $\mathrm{V}_{3}$, helps support our hypothesis about the role and contribution of the suboccipital cavernous sinus in the regulation of "pressure."

Despite certain variations, the $\mathrm{V}_{3}$ maintains basic anatomical and functional[42] properties. Although it adapts readily to movements at the craniospinal joint, if the rotations of the head and neck are pronounced and sudden, the artery can be subjected to shearing forces.[19,63] The tight anatomical relations among the third muscular layer, the craniocervical bone joint, the $\mathrm{C}-1$ and $\mathrm{C}-2$ nerves, and the $\mathrm{V}_{3}$ create the potential for neurovascular compression, with resulting clinical symptoms.[71] The complete incorporation of the $\mathrm{V}_{3} \mathrm{~h}$ by bone at the posterior arch of the atlas has been reported to occur in 7.8 to $28 \%$ of cases.[1,14,61] In our study, it occurred in $20 \%$ of the cases, always unilaterally. The possibility of such complete bone bridging of the $\mathrm{V}_{3} \mathrm{~h}$ from the atlas, in approximately every fifth patient, should be anticipated before the surgery. The asymmetry of VAs has been reported, with the larger artery occurring more often on the left side[24,69] and called the dominant artery versus a contralateral minor artery.[24] The size of the transverse foramen of the axis also has been found to be larger on the left side.[20] In addition to confirming these findings, our study showed that almost all the mean values of the measurements obtained were greater for the left side (Tables 1-3), the reason for which remains unknown.

\section{Branches of $V_{3}$ and Their Functional Significance}

The posterior meningeal artery (Fig. 6), which arises from the posterosuperior surface of the $\mathrm{V}_{3} \mathrm{~h}$ at its superior medial loop, vascularizes the neighboring portion of the posterior fossa dura. It belongs to the "posterior meningeal vascularization system,"[19] with the branches from the OA, the ascending pharyngeal artery, and the $\mathrm{V}_{2}$ segment of the VA (anterior meningeal artery). This meningeal branch of $\mathrm{V}_{3}$ arising within the suboccipital cavernous sinus also communicates with the dorsal meningeal artery, which is a branch of the meningohypophyseal trunk arising within the cavernous sinus.[50] It can participate in the vascularization of meningiomas, glomus jugulare tumors, hemangioblastomas, and dural arteriovenous malformations (AVMs) of the transverse sigmoid sinus.[14,37,45]

After passing through the foramen of the atlantooccipital membrane, the muscular artery of $\mathrm{V}_{3} \mathrm{~h}(\mathrm{Fig} .7$ right) communicates with the branches of the OA (Fig. 2). These communications are seen in only $1 \%$ of angiographic studies, but they have been detected often in postmortem studies.[40,56] We detected this physical presence in $80 \%$ of the specimens. This branch of $\mathrm{V}_{3} \mathrm{~h}$, described also as "Salmon's suboccipital artery,"[19,24] has rich communications contained in a suboccipital (cervical) arterial collateral network. $[10,19,46]$ Other arteries involved in this network are the muscular branches of the OA and the branches of the thyrocervical and costocervical trunks. An important aspect of the connections between the $\mathrm{V}_{3}$ and the $\mathrm{OA}$ is their potential to develop and maintain adequate blood flow when occlusive vascular disorders of the ICA or the VA interrupt the normal pathways. Under such circumstances, these communications can enlarge and occur either indirectly via the suboccipital muscles or directly. 
However, the stenotic lesions of the VA are not as frequent as those of the ICA.[10,19,22,40,46,53,56,70]

The radiculomuscular artery of $\mathrm{V}_{3} \mathrm{v}$ (Fig. 7), the largest branch of the $\mathrm{V}_{3}$, has two branches: 1) a medial branch that vascularizes the spinal nerve and its ganglion and penetrates the dura, contributing to the perimedullary arterial vasocorona of the spinal cord; and 2) a lateral branch that vascularizes the suboccipital muscles and also participates in the suboccipital collateral arterial network.[19]

The muscular artery of the $\mathrm{V}_{3} \mathrm{v}$ (Fig. 7 left), which arises at the ventral portion of the inferolateral arterial loop, is rarely and only indirectly reported in the literature, $[35,46]$ probably because of its tiny size, hidden position, and difficulties encountered in its preservation during dissection. We frequently see this artery during surgery and must divide it during the caudomedial transposition of the $\mathrm{V}_{3}$. It communicates with the branches of the ascending pharyngeal artery, which contribute to the vascularization of a glomus jugulare tumor; $[39,46,68]$ thus, this $\mathrm{V}_{3} \mathrm{v}$ branch contributes also to the vascularization of the glomus tumor and, presumably, contributes to the suboccipital arterial collateral network.

\section{Role of Venous Structures in Accessory Venous Drainage From the Intracranium}

The suboccipital cavernous sinus and its inferior continuation below the transverse foramen of the atlas, the VAVP, should be clearly distinguished from the VVP, which Batson[6,7] calls the vertebral venous system (VVS).

The VVP has two components; the internal, which lies within the spinal canal, and the external, which is found predominantly around the vertebral column.[13,18,38] At every vertebral interspace, these components are connected by the intervertebral veins.[4,6,7,13,35] The VVP has been described as either an accessory route of venous return from the intracranium during the flexion and extension, as well as during the rise in the intraabdominal or interbody pressure, $[6,7,13,30,57]$ or a major route for venous intracranial outflow, particularly when the body is in an upright position. $[16,18]$ Hence, this plexus provides independent accessory venous drainage from the intracranial compartment. Moreover, as we have shown, the plexus communicates with bilateral suboccipital cavernous sinuses at the occipitoatlantal interspace (Figs. 2, 3 C, and 4) and from the VAVP at the atlantoaxial interspace (Fig. 3C). After the bilateral gradual ligation of jugular veins, the VVP assumes the role of venous drainage from the intracranial compartment,[6,7,11-13,71] during which the contrast medium has also been detected exiting the cavernous sinus through the ophthalmic and the pterygoid plexuses.[11,13] Because the adult configuration of cranial venous development is not complete at birth, subsequent communications permit the secondary cavernous and inferior petrosal sinuses to supplement the drainage of the internal jugular system.[48] Sljivic, et al.,[60] reported that the occipital dural sinus is well developed in $60 \%$ of the population and may, in the case of bilateral IJV resection, maintain the venous drainage from the intracranial compartment farther to the VVP. According to these authors, in the remaining $40 \%$ of the population, who have a rudimentary or no occipital dural sinus, this procedure is fatal.

In addition to confirming that the VVP is a direct continuation of the cranial venous sinuses, $[13,73]$ our study showed that it is also indirectly connected to these sinuses via the suboccipital cavernous sinus (Figs. $3 \mathrm{~A}, \mathrm{~B}, \mathrm{C}$, and 4). The VVP is involved in regulating intracranial pressure, transmitting the influence of the respiratory and cardiac pressures to the intracranial compartment and equalizing the pressures within the venous system.[28,30,73] Because of its position and connections, the suboccipital 
cavernous sinus undoubtedly is a functional part of the VVS, together with the internal and the external components of the VVPs, and therefore at least shares with the VVP the function described variously as "the only true alternative pathway for venous drainage from the intracranium;"[30] "secondary drainage system from intracranial compartment;"[12] or "an important cerebral venous outflow tract especially in sitting or standing position."[16,18] The suboccipital cavernous sinus has, however, an additional and more independent and important "relay station" role, having multiple communications of variable sizes and being interposed among: 1 ) the cranial venous sinuses[43,65] (communication with the confluens sinuum via occipital and marginal dural sinuses; communication with the ipsilateral and contralateral inferior petrosal and cavernous sinuses via plexus basilaris); 2) the internal jugular bulb and IJV (as a principal venous draining system from intracranium); and 3) the VVS (external and internal VVPs) (Fig. $3 \mathrm{~B}$ and $\mathrm{C})$.

A rich suboccipital venous plexus, located between the intermediate and deep muscular layers (Fig. 1 upper), communicates with the surrounding venous structures. We confirmed that this plexus receives communication from the transverse sinus via the mastoid emissary and occipital veins, supporting the statement by Cooper[13] that this plexus is a functional part of the VVP. This plexus may be the source of air embolisms when the patient is in the sitting operative position, which must be kept in mind during surgery.

\section{Role of the VVS in Metastatic Spread of Diseases to Intracranium}

Approximately 20 to $40 \%$ of cancer patients develop intracranial metastases. The role of the VVS (VVP) in the metastatic spread of diseases to the intracranial compartment, bypassing the lungs, was shown experimentally and explained by Batson,[6,7] who also elucidated its multiple and rich venous communications, very low intraluminal pressures, slow circulation, and lack of valves. In such patients, repeated rises in the intrathoracic pressure due to body posture, sneezing, straining, or coughing contribute to the increased blood flow through the VVP and subsequent neoplastic, inflammatory, or thrombotic metastasis to the brain. $[4,6,7,30,58,64]$ This transvenous mechanism is far more common in the pathogenesis of cerebral metastasis than the proposed mechanism of "paradoxical embolism" of the body tumor along the arterial tree, which is necessarily associated with persistent heart septal defects.[4,29,47] Hence, because of its interrelations with the VVS, the suboccipital cavernous sinus is most likely also involved in the metastatic spread of diseases.

\section{Surgical Considerations}

The $\mathrm{V}_{3}$ can be approached via the lateral route between the sternocleidomastoid muscle and the lateral border of the IJV. Care should be taken to preserve the accessory nerve. In addition to the $\mathrm{V}_{3}$ itself, the targeted pathological entities include AVMs, tumors, osteophytes, fibrous bands, infective processes, and traumatic lesions. One cautionary note is that rotating the head of the anesthetized patient during the surgical positioning can cause intermittent stenosis or even occlusion of the VA.[23,24]

Surgical caudomedial transposition of the $\mathrm{V}_{3}$ is performed during transcondylar approaches to ventral lesions located at the lower clivus, the anterior part of the craniocervical junction, the lower brainstem, and the upper cervical cord. These lesions include tumors (meningiomas, neurinomas, neurofibromas, and chordomas), vascular lesions (AVMs or aneurysms), degenerative diseases (rheumatoid arthritis), congenital malformations, and traumatic lesions.[2,5,8,31,59] After the $\mathrm{V}_{3}$ has been dissected from the transverse foramen of the axis to its dural entry, the posterior wall of the transverse foramen of the atlas 
is opened using a diamond drill. Careful subperiosteal dissection spares the lateral (periosteal) ring (Figure 3 upper left and center), which may be used for surgical manipulation during the transposition. Cautious surgical dissection, opening of the posterior atlantooccipital membrane (Fig. 2), division of the retroglenoid ligament (Fig. 7 right), early coagulation and division of the condylar anastomotic veins (Fig. $3 \mathrm{~A}, \mathrm{~B}$, and C), and preservation of the fibrous membrane surrounding the suboccipital cavernous sinus itself (Fig. 3 A, B, C, and D) should be implemented to minimize bleeding. If bleeding does occur, it usually can be easily controlled by packing because of the low intraluminal venous pressure. The $\mathrm{V}_{3}$ is transposed caudomedially to gain space for drilling the occipital condyle and the lateral mass of the atlas.[2] Care should be taken while opening the dura at the distal (dural) ring (Fig. 6) to preserve the C-1 nerve inferior to the artery and the origin of the posterior spinal artery behind the $\mathrm{V}_{3} \mathrm{~h}$ (if it exists). The dura mater in this region is thicker than usual and contains venous channels of various sizes (the VVP). Maintaining an adequate dural cuff around the artery is important for a watertight dural closure that will prevent a cerebrospinal fluid leak.[14,59]

The median inferior suboccipital approach through the vertical midline incision from the occipital protuberance down to C2-3 is used commonly to excise many lesions, including foramen magnum meningiomas, cerebellar hemangioblastomas and astrocytomas, vermian and fourth ventricular tumors, and medullary and cervicomedullary astrocytomas.[68] If the incision is made in the strict midline position, the $V_{3}$ is not encountered;[14] nevertheless, the surgeon must appreciate the unseen course of the $\mathrm{V}_{3}$.

The $\mathrm{V}_{3}$ may provide arterial blood supply to the upper dorsal cervical tumors or vascular lesions, either directly or indirectly by one of its branches. For glomus jugulare tumors, embolization and ligation of the feeding vessels suppresses the tumor vascularization and makes the definite tumor excision easier. Obtaining pre- and postoperative angiograms is essential.[9,44,68]

\section{CONCLUSIONS}

The suboccipital cavernous sinus and the cavernous sinus are quite analogous anatomical complexes. The anatomic properties of their contents (the venous cushioning, the $\mathrm{V}_{3}$ and the petrous-cavernous ICA, the arterial loops and the supporting fibrous rings, the arterial branches, the periarterial autonomic neural plexuses, the surrounding nerves, and transitional patterns of the arterial walls of the $\mathrm{V}_{3}$ and of the petrous-cavernous ICA), their embryological development, their locations at the base of the skull, and their neurosurgical importance are all quite similar. Besides being morphological entities, they also play active and important functional roles. 


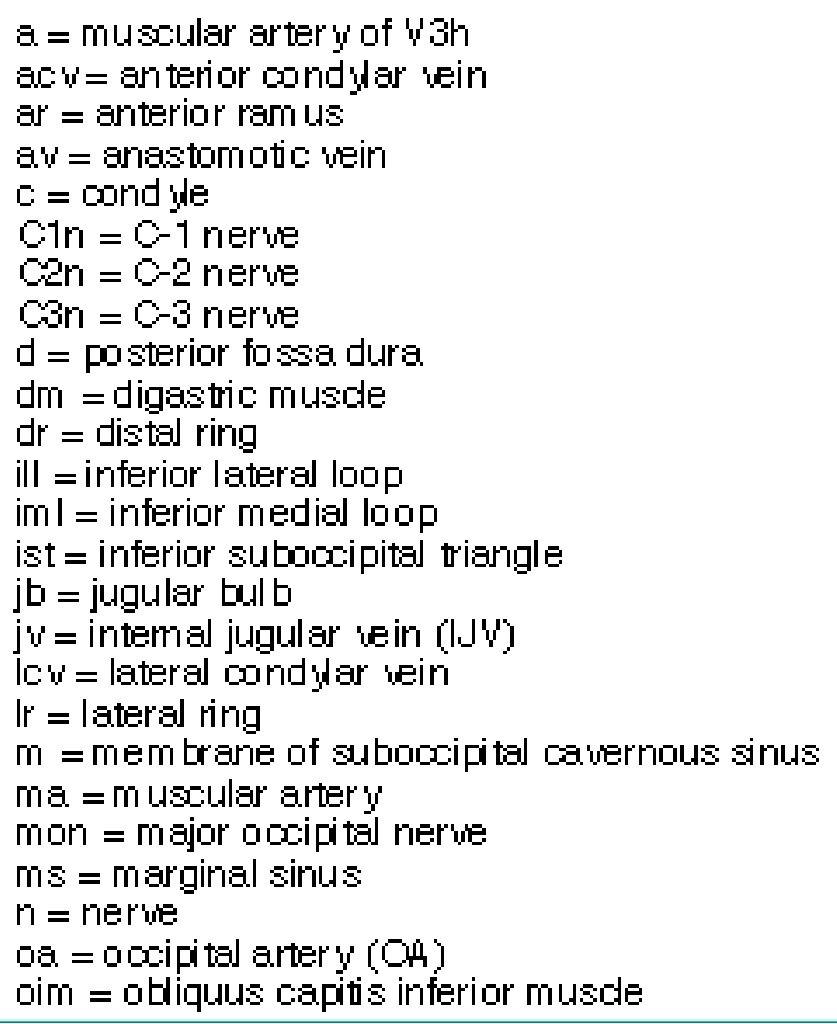

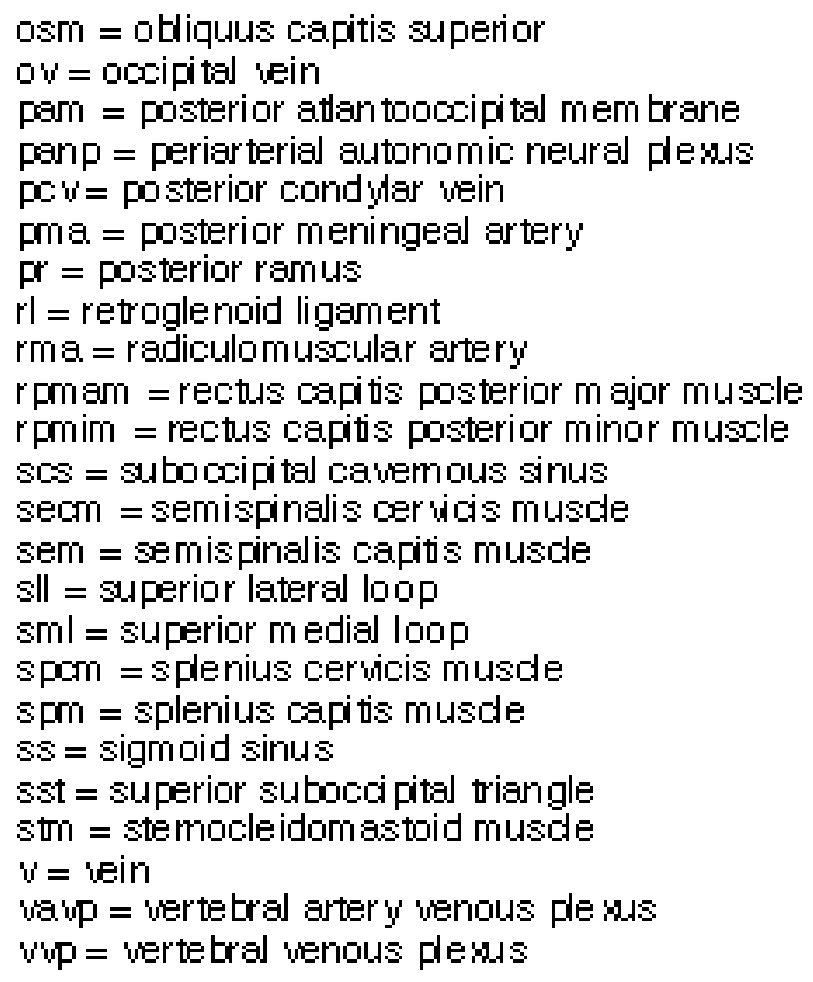

\section{Acknowledgments}

The authors thank Dr. B. Lee Ligon for editorial assistance, Dr. Robert C. Walls for statistical analysis, and Mr. Ron M. Tribell for original artwork. We also appreciate the assistance of Dr. Patrick W. Tank, Department of Anatomy, who provided anatomical specimens.

\section{References}

1. Abd El-Bary TH, Dujovny M, Ausman JA: Microsurgical anatomy of the atlantal part of the vertebral artery. Surg Neurol 44:392-401, 1995

2. Al-Mefty O, Borba LAB, Aoki N, et al: The transcondylar approach to extradural nonneoplastic lesions of the craniovertebral junction. J Neurosurg 84:1-6, 1996

3. Al-Mefty O, Smith RR: Surgery of tumors invading the cavernous sinus. Surg Neurol 30:370-381, 1988

4. Anderson R: Diodrast studies of the vertebral and cranial venous systems. To show their probable role in cerebral metastases. J Neurosurg 8:411-422, 1951

5. Baldwin HZ, Miller CG, van Loveren HR, et al: The far lateral/combined supra- and infratentorial approach. A human cadaveric prosection model for routes of access to the petroclival region and ventral brain stem. J Neurosurg 81:60-68, 1994

6. Batson OV: The function of the vertebral veins and their role in the spread of metastases. Ann Surg 
112:138-149, 1940

7. Batson OV: The vertebral vein system. AJR 78:195-212, 1957

8. Bertalanffy H, Seeger W: The dorsolateral, suboccipital, transcondylar approach to the lower clivus and anterior portion of the craniocervical junction. Neurosurgery 29:815-821, 1991

9. Borba LAB, Al-Mefty O: Intravagal paragangliomas: report of four cases. Neurosurgery 38:569-575, 1996

10. Bosniak MA: Cervical arterial pathways associated with brachiocephalic occlusive disease. AJR 91:1232-1244, 1964

11. Bowsher DR: Connexions of the internal vertebral venous plexus. J Anat 88:583, 1954 (Abstract)

12. Braun JP, Tournade A: Venous drainage in the craniocervical region. Neuroradiology 13:155-158, 1977

13. Cooper ERA: The vertebral venous plexus. Acta Anat 42:333-351, 1960

14. de Oliveira E, Rhoton AL Jr, Peace D: Microsurgical anatomy of the region of the foramen magnum. Surg Neurol 24:293-352, 1985

15. Dolenc VV: Anatomy and Surgery of the Cavernous Sinus. Vienna: Springer-Verlag, 1989

16. Eckenhoff JE: The vertebral venous plexus. Can Anaesth Soc J 18:487-495, 1971

17. Ehrlich FE, Carey L, Kitrinos NP: Congenital arteriovenous fistula between the vertebral artery and vertebral vein. Case report. J Neurosurg 29:629-630, 1968

18. Epstein HM, Linde HW, Crampton AR, et al: The vertebral venous plexus as a major cerebral venous outflow tract. Anesthesiology 32:332-337, 1970

19. Francke JP, Di Marino V, Pannier M, et al: The vertebral arteries (arteria vertebralis). The V3 atlanto-axoidial and V4 intracranial segments-collaterals. Anat Clin 2:229-242, 1981

20. Gabrielsen TO: Size of vertebral artery and of foramen transversarium of axis. An anatomic study. Acta Radiol (Diagn) 9:285-291, 1969

21. George B, Damatons C, Cophignon J: Lateral approach to the anterior portion of the foramen magnum. Application to surgical removal of 14 benign tumors: technical note. Surg Neurol 29:484-490, 1988

22. George B, Laurian C: Impairment of vertebral artery flow caused by extrinsic lesions. Neurosurgery 24:206-214, 1989

23. George B, Laurian C: Surgical approach to the whole length of the vertebral artery with special reference to the third portion. Acta Neurochir 51:259-272, 1980

24. George B, Laurian C: The Vertebral Artery. Pathology and Surgery. Vienna: Springer-Verlag, 1987

25. George B, Laurian C: Vertebro-basilar ischaemia. Its relation to stenosis and occlusion of the 
vertebral artery. Acta Neurochir 62:287-295, 1982

26. Gilmore SA: Developmental anatomy of the intracranial venous system: review of dural venous system development, in Hakuba A (ed): Surgery of the Intracranial Venous System. New York: Springer-Verlag, 1996, pp 3-13

27. Hakuba A, Ohata K, Nakanishi N, et al: Developmental anatomy of the cavernous sinus, in Hakuba A (ed): Surgery of the Intracranial Venous System. New York: Springer-Verlag, 1996, pp 26-35

28. Hamilton WF, Woodbury RA, Harper HT Jr: Physiologic relationships between intrathoracic, intraspinal and arterial pressures. JAMA 107:853-856, 1936

29. Harris HA: A note on the clinical anatomy of the veins, with special reference to the spinal veins. Brain 64:291-300, 1941

30. Herlihy WF: Revision of the venous system: the role of the vertebral veins. Med J Australia 1:661-672, 1947

31. Hosoda K, Fujita S, Kawaguchi T, et al: A transcondylar approach to the arteriovenous malformation at the ventral cervicomedullary junction: report of three cases. Neurosurgery 34:748-753, 1994

32. Kimmel DL: The cervical sympathetic rami and the vertebral plexus in the human fetus. J Comp Neurol 112:141-157, 1959

33. Kimmel DL: Innervation of spinal dura mater and dura mater of the posterior cranial fossa.

Neurology 11:800-809, 1961

34. Kimmel DL: Rami communicantes of cervical nerves and the vertebral plexus in the human embryo. Anat Rec 121:321-322, 1955 (Abstract)

35. Lang J: Clinical Anatomy of the Cervical Spine. Stuttgart: Thieme, 1993

36. Lang J: Craniocervical region, blood vessels. Neuroorthopedics 2:55-69, 1986

37. Lang J: Craniocervical region, surgical anatomy. Neuroorthopedics 3:1-26, 1987

38. Lang J, Kessler B: About the suboccipital part of the vertebral artery and the neighboring bone-joint and nerve relationships. Skull Base Surg 1:64-71, 1991

39. Lasjaunias $\mathrm{P}$, Moret J: The ascending pharyngeal artery: normal and pathological radioanatomy. Neuroradiology 11:77-82, 1976

40. Lasjaunias P, Théron J, Moret J: The occipital artery. Anatomy--normal arteriographic aspects--embryological significance. Neuroradiology 15:31-37, 1978

41. Marinkovic S, Milisavljevic M: Arterije Mozga. Anatomske i Klinicke Karakteristike. Belgrad: Bit Inzenjering, 1990

42. Maslowski HA: The role of the vertebral artery. J Neurol Neurosurg Psychiatry 23:355, 1960 (Abstract)

43. Matsushima T, Rhoton AL Jr, de Oliveira E, et al: Microsurgical anatomy of the veins in the 
posterior fossa. J Neurosurg 59:63-105, 1983

44. Merland JJ, Riche MC, George B, et al: Current trends in the combined radiological and surgical management of vascular malformations, tumours and displasias involving the vertebral artery. $\mathbf{J}$ Neuroradiol 6:269-286, 1979

45. Newton TH: The anterior and posterior meningeal branches of the vertebral artery. Radiology 91:271-279, 1968

46. Nierling DA, Wollschlaeger PB, Wollschlaeger G: Ascending pharyngeal-vertebral anastomosis. AJR 98:599-601, 1966

47. Norgore M: Clinical anatomy of the vertebral veins. Surgery 17:606-615, 1945

48. Padget DH: The cranial venous system in man in reference to development, adult configuration, and relation to the arteries. Am J Anat 98:307-355, 1956

49. Parke WW, Valsamis MP: The ampulloglomerular organ: an unusual neurovascular complex in the suboccipital region. Anat Rec 159:193-198, 1967

50. Parkinson D: Lateral sellar compartment: history and anatomy. J Craniofac Surg 6:55-68, 1995

51. Parkinson D: A surgical approach to the cavernous portion of the carotid artery. Anatomical studies and case report. J Neurosurg 23:474-483, 1965

52. Platzer W (ed): Pernkopf Anatomy. Atlas of Topographic and Applied Anatomy, ed 3. Baltimore: Urban \& Schwarzenberg, 1989, Vol 1, p 114

53. Richter HR: Collaterals between the external carotid artery and the vertebral artery in cases of thrombosis of the internal carotid artery. Acta Radiol 40:108-112, 1953

54. Rickenbacher J: Der suboccipitale und der intrakraniale Abschnitt der Arteria Vertebralis. Z Anat Entwicklungsgesch 124:171-178, 1964

55. Rogers LC, Payne EE: The dura mater at the cranio-vertebral junction. J Anat 95:586-588, 1961

56. Schechter MM: The occipital-vertebral anastomosis. J Neurosurg 21:758-762, 1964

57. Schobinger R, Lessmann FP: A new approach allowing the roentgenologic demonstration of the cervical vertebral venous plexi. Exp Med Surg 15:289-299, 1957

58. Scrimgeour EM, Gajdusek DC: Involvement of the central nervous system in Schistosoma Mansoni and S. Haematobium infection. A review. Brain 108:1023-1038, 1985

59. Sen CN, Sekhar LN: An extreme lateral approach to intradural lesions of the cervical spine and foramen magnum. Neurosurgery 27:197-204, 1990

60. Sljivic B, BoskovicM, Savic V: Morphological varieties of the occipital sinus and its prognostic value following bilateral resection of internal jugular veins. Anat Rec 136:279, 1960 (Abstract)

61. Taitz C, Nathan H: Some observations on the posterior and lateral bridge of atlas. Acta Anat 127:212-217, 1986 
62. Taptas JN: The so-called cavernous sinus: a review of the controversy and its implications for neurosurgeons. Neurosurgery 11:712-717, 1982

63. Toole JF: Cerebrovascular Disorders, ed 4. New York: Raven Press, 1990, pp 12-25

64. Vider M, Maruyama Y, Narvaez R: Significance of the vertebral venous (Batson's) plexus in metastatic spread in colorectal carcinoma. Cancer 40:67-71, 1977

65. Wackenheim A, Braun JP: The Veins of the Posterior Fossa. Berlin: Springer-Verlag, 1978

66. Wilkinson IMS: The vertebral artery. Extracranial and intracranial structure. Arch Neurol 27:392-396, 1972.

67. Williams PL, ed: Gray's Anatomy, ed 38. New York: Churchill Livingstone, 1995, p 1586

68. Yasargil MG: Microneurosurgery. Microneurosurgery of CNS tumors. New York: Thieme, Vol IVb, 1996

69. Yasargil MG: Microsurgery. Applied to Neurosurgery. New York: Thieme, 1969, pp. 82-88

70. Youmans JR, Scarcella G: Extracranial collateral cerebral circulation. Neurology 11:166-169, 1961

71. Zaitseva RL, Chudnovskii NA: Osobennosti topografoanatomicheskikh vzaimootnoshenii pozvonochroi arterii, myshts, soedinitel'notkannykh i nervnykh obvazovanii v oblasti atlantozatylochungo sustava. Arkh Anat Gistol Embriol 84:23-29, 1983

72. Zolnai B: Die zwischen der Arteria Vertebralis und den vertebralen und zerbralen Venen bestehende Verbindung am atlantookzipitalen Abschnitt beim Menschen. Anat Anz Bd 114:400-407, 1964

73. Zouaoui A, Hidden G: Le plexus veineux vertébral cervical et anastomoses avec les sinus veineux craniens. Bull Assoc Anat 71:7-13, 1987

Manuscript received April 18, 1996.

Accepted in final form September 23, 1996.

Address reprint requests to: Ossama Al-Mefty, M.D., Department of Neurosurgery, University of Arkansas for Medical Sciences, 4301 West Markham, Slot 507, Little Rock, Arkansas 72205. 